\title{
Mixed function oxidases in response to different types of dietary lipids in rats
}

\author{
BY MORIO SAITO ${ }^{1}$, AKIRA OH-HASHI ${ }^{1}$, MIKA KUBOTA ${ }^{1}$, EIICHI NISHIDE ${ }^{2}$ \\ AND MICHIO YAMAGUCHI ${ }^{1}$ \\ ${ }^{1}$ Division of Food Science, National Institute of Health and Nutrition, 1-23-1, Toyama, \\ Shinjuku-ku, Tokyo 162, Japan \\ ${ }^{2}$ Department of Fisheries, College of Agriculture and Veterinary Medicine, Nihon University, \\ Tokyo 154, Japan
}

(Received 28 October 1988-Accepted 9 August 1989)

\begin{abstract}
The influence of dietary lipids on the liver microsomal mixed function oxidase system and on pentobarbital-induced sleeping time was studied in rats. Giving diets containing $(\mathrm{g} / \mathrm{kg}) 150$ olive oil, 150 lard or 150 soya-bean oil for $21 \mathrm{~d}$ (Expt 1) increased the cytochrome P-450 content in the order: olive oil $<$ lard < soya-bean oil. When diets containing (g/kg) 150 lard, 150 soya-bean oil, 150 sardine oil or an equal mixture of 50 of each oil were given for $15 \mathrm{~d}$ (Expt 2), the cytochrome P-450 content and aminopyrine $\boldsymbol{N}$-demethylase activity were significantly higher in the sardine-oil and mixed-oil groups than in the lard group, and the activity of aminopyrine $N$-demethylase was also significantly higher in the soyabean oil group compared with the lard group. A significantly higher activity of NADPH-cytochrome $c$ reductase $(E C$ 1.6.2.5) was observed in the sardine-oil group than in the other three groups. Aniline hydroxylase activity and cytochrome $b_{5}$ content remained unchanged in all the groups. Pentobarbitalinduced sleeping time measured on day 15 (Expt 2) varied inversely with the changes in cytochrome P450 content and aminopyrine $N$-demethylase activity in the three single-fat groups, but not in the mixedoil group, reflecting liver microsomal metabolic activity for pentobarbital in vivo. From these results, it appears that high intakes of polyunsaturated fatty acids $(18: 2 n-6,18: 3 n-3,20: 5 n-3$ and $22: 6 n-3)$ stimulate the liver microsomal mixed function oxidase system.
\end{abstract}

Dietary lipids: Mixed function oxidase: Sleeping time: Rat

The cytochrome P-450-dependent liver microsomal mixed function oxidase system plays an important role in the metabolism of a wide variety of drugs and foreign compounds, and of some endogenous substances such as cholesterol and hormones. The activity of the mixed function oxidase system is known to be influenced by nutritional factors (Miller, 1976; Anderson et al. 1982). The mixed function oxidases are membrane-bound and phosphatidylcholine, as one of the structural components of microsomal membranes, is necessary for proper function of the system $(\mathrm{Lu}, 1976)$. Variations in dietary lipids with different fatty acids produce corresponding variations in the fatty acid composition of phospholipids of the microsomal membranes (Laitinen et al. 1975) and, thus, alter the membrane conformation and fluidity, resulting in changes in the activity of mixed function oxidases.

Previous studies have indicated that elevation of polyunsaturated fatty acid intake increases the activity of the liver microsomal mixed function oxidase system (Kaschnitz, 1970; Century, 1973; Wade \& Norred, 1976; Hammer \& Wills, 1979; Clinton et al. 1984). In particular, Hammer \& Wills (1979) present very intriguing findings that dietary linoleic acid $(18: 2 n-6)$ is important in the regulation of the rate of oxidative demethylation in liver microsomes and may be replaced effectively by dietary eicosapentaenoic $(20: 5 n-3)$ and docosahexaenoic (22:6n-3) acids. Wade et al. (1972) also suggest a similar involvement of 
dietary fatty acids such as arachidonic acid (20:4n-6) and $22: 6 n-3$. However, almost no effect of polyunsaturated fatty acid intake on some of the mixed function oxidases has been observed (Norred \& Wade, 1972; Wade et al. 1972; Century, 1973; Meydani et al. 1985); on the contrary, a high intake of $18: 2 n-6$ prolongs pentobarbitone-induced sleeping time due to lowered activity of the mixed function oxidase system (Hopkins \& West, 1976). The results of these studies have not always been consistent. The present studies extend and confirm the studies of Hammer \& Wills (1979).

\section{MATERIALS AND METHODS}

\section{Animals and diets}

Male Sprague-Dawley rats (Murai Laboratory Animals Co. Ltd, Saitama, Japan), 4 weeks of age, weighing $75-85 \mathrm{~g}$, were used in all experiments. The compositions of the basal and experimental diets $(\mathrm{g} / \mathrm{kg}$ diet) based on $\mathrm{AIN}-76$ purified diet for rats (Bieri et al .1977 ) are shown in Table 1. Rats were fed on the basal diet for $3 \mathrm{~d}$ and then randomly assigned to the experimental diets. Food and water were available $a d$ lib. Throughout the experiments, the rats were individually housed in stainless steel, wire-bottomed cages at a constant temperature of $22 \pm 1^{\circ}$ and humidity of $50-60 \%$. Lighting was from 07.00 to 19.00 hours. Fatty acid composition $(\mathrm{g} / 100 \mathrm{~g})$ of dietary lipids is indicated in Table 2. Olive oil is rich in oleic acid (18:1n-9), lard is rich in $18: 1 n-9$ and saturated fatty acids, soya-bean oil provided significant amounts of $18: 2 n-6$ and $18: 3 n-3$, and sardine oil supplied $20: 5 n-3$ and 22:6n-3. To prevent autoxidation of sardine oil in a diet, the diet was prepared beforehand without sardine oil and stored at $-20^{\circ}$ and the oil was mixed with the diet every day immediately before feeding. The vitamin $\mathrm{E}$ ( $\alpha$-tocopherol equivalent) concentrations of the oils $(\mathrm{mg} / \mathrm{kg}$ ) were: olive oil $75 \cdot 2$, lard $7 \cdot 6$, soya-bean oil $85 \cdot 4$, sardine oil $43 \cdot 4$. The relative biological activities for $\alpha-, \beta-, \gamma$ - and $\delta$-tocopherols were taken as $100: 25: 5: 0 \cdot 1$ in the calculation (Mino et al. 1988).

\section{Expt 1}

Groups of five to six rats were fed on the experimental diets containing $(\mathrm{g} / \mathrm{kg}) 150$ olive oil, 150 lard or 150 soya-bean oil for $21 \mathrm{~d}$. After fasting overnight, the rats were decapitated and the livers were promptly excised, washed with isotonic saline ( $9 \mathrm{~g}$ sodium chloride/l), weighed, and then perfused with ice-cold isotonic saline via the portal vein. The livers were stored at $-80^{\circ}$ until analysis for determination of the liver microsomal cytochrome P-450 content.

\section{Expt 2}

Groups of nine rats were given the experimental diets containing (g/ kg) 150 lard, 150 soyabean oil, 150 sardine oil, or an equal mixture of 50 of each oil for $15 \mathrm{~d}$. On day 15 , pentobarbital-induced sleeping time was measured by intraperitoneal injection of $50 \mathrm{mg}$ sodium pentobarbital $/ \mathrm{kg}$ in isotonic saline. The time from loss to recovery of the righting reflex was taken as the experimental sleeping time induced by the drug. The rats were decapitated immediately after recovery from sleeping and treated as described in Expt 1 . Liver microsomal cytochrome P-450 and cytochrome $b_{5}$ contents, and activities of NADPH-cytochrome $c$ reductase $(E C 1.6 .2 .5)$, aminopyrine $N$-demethylase and aniline hydroxylase were determined.

\section{Analytical methods}

Determination of the fatty acid composition of dietary lipids. Fatty acid methyl esters of dietary lipids were prepared as follows: lipids were saponified with $0.5 \mathrm{M}$-sodium hydroxide-methanol solution and the resultant free fatty acids were converted into methyl esters using boron trifluoride-methanol solution $(140 \mathrm{~g} / \mathrm{l})$. The methyl esters were extracted with $n$-hexane and quantified by gas-liquid chromatography (Shimadzu GC-8A gas-liquid 
Table 1. Compositions of basal and experimental diets $(\mathrm{g} / \mathrm{kg}$ diet $)$

\begin{tabular}{lrr}
\hline Ingredients & Basal & Experimental \\
\hline Casein & $200 \cdot 0$ & $200 \cdot 0$ \\
DL-Methionine & $3 \cdot 0$ & $3 \cdot 0$ \\
Maize starch & $150 \cdot 0$ & $150 \cdot 0$ \\
Sucrose & $250 \cdot 0$ & $200 \cdot 0$ \\
Glucose & $250 \cdot 0$ & $200 \cdot 0$ \\
Cellulose & $50 \cdot 0$ & $50 \cdot 0$ \\
Mineral mixture (AIN $\dagger$ ) & $35 \cdot 0$ & $35 \cdot 0$ \\
Vitamin mixture (AIN $\dagger$ ) & $10 \cdot 0$ & $10 \cdot 0$ \\
Choline bitartrate & $2 \cdot 0$ & $2 \cdot 0$ \\
Soya-bean oil & $50 \cdot 0$ & - \\
Test lipids & - & $150 \cdot 0$ \\
\hline
\end{tabular}

$\uparrow$ Bieri et al. (1977).

Table 2. Fatty acid composition $(\mathrm{g} / 100 \mathrm{~g})$ of dietary lipids given to rats

\begin{tabular}{lrrrrr}
\hline \hline Fatty acid & Olive oil & Lard & Soya-bean oil & Sardine oil & Oil mixture* \\
\hline $14: 0$ & - & $1 \cdot 8$ & - & $8 \cdot 0$ & $3 \cdot 5$ \\
$16: 0$ & $11 \cdot 6$ & $23 \cdot 3$ & $10 \cdot 7$ & $16 \cdot 3$ & $17 \cdot 1$ \\
$16: 1 n-7$ & $1 \cdot 2$ & $4 \cdot 1$ & - & $9 \cdot 2$ & $4 \cdot 8$ \\
$18: 0$ & $2 \cdot 9$ & $11 \cdot 0$ & $3 \cdot 7$ & $2 \cdot 4$ & $6 \cdot 3$ \\
$18: 1 n-9$ & $77 \cdot 0$ & $46 \cdot 0$ & $23 \cdot 5$ & $12 \cdot 9$ & $27 \cdot 9$ \\
$18: 2 n-6$ & $6 \cdot 6$ & $10 \cdot 8$ & $53 \cdot 6$ & $3 \cdot 3$ & $22 \cdot 2$ \\
$18: 3 n-3$ & $0 \cdot 8$ & $1 \cdot 8$ & $8 \cdot 5$ & $7 \cdot 0$ & $5 \cdot 6$ \\
$18: 4 n-3$ & - & - & - & $3 \cdot 5$ & $1 \cdot 1$ \\
$20: 4 n-6$ & - & - & - & $5 \cdot 3$ & $1 \cdot 8$ \\
$+22: 1 n-11$ & - & - & - & $15 \cdot 1$ & $5 \cdot 1$ \\
$20: 5 n-3$ & - & - & - & $2 \cdot 2$ & $0 \cdot 7$ \\
$22: 5 n-3$ & - & - & - & $10 \cdot 3$ & $3 \cdot 5$ \\
$22: 6 n-3$ & - & $1 \cdot 2$ & - & $4 \cdot 4$ & $0 \cdot 5$ \\
Others & $14 \cdot 5$ & $36 \cdot 1$ & $14 \cdot 4$ & $26 \cdot 7$ & $26 \cdot 9$ \\
Saturated $\dagger$ & $78 \cdot 2$ & $50 \cdot 1$ & $23 \cdot 5$ & $22 \cdot 1$ & $32 \cdot 7$ \\
Monounsaturated $\dagger$ & $12 \cdot 6$ & $62 \cdot 1$ & $47 \cdot 6$ & $40 \cdot 0$ \\
Polyunsaturated $\dagger$ & $7 \cdot 4$ & & & \\
\hline \hline
\end{tabular}

* An equal mixture of lard, soya-bean oil and sardine oil.

$\dagger$ Total percentages of saturated, monounsaturated and polyunsaturated fatty acids respectively.

chromatograph, Tokyo, Japan) using a $2.5 \mathrm{~mm} \times 2 \mathrm{~m}$ glass column containing diethylene glycol succinate on $80 / 100$ mesh Uniport HP $(150 \mathrm{~g} / \mathrm{kg})$. Injector and column temperatures were $240^{\circ}$ and $190^{\circ}$ respectively. Nitrogen was employed as the carrier gas. Standard mixtures of fatty acid methyl esters (Nihon Chromato Works Ltd, Tokyo, Japan) were used for identification of peaks.

Mixed function oxidase analyses. Liver microsomes were prepared as described previously (Saito \& Yamaguchi, 1988). Contents of cytochromes P-450 and $b_{5}$ were measured by the methods of Omura \& Sato (1964) and NADPH-cytochrome $c$ reductase activity by the method of Omura \& Takesue (1970). Assay conditions for measurement of aminopyrine $\mathrm{N}$ demethylase and aniline hydroxylase activities were those reported previously by Saito \& Yamaguchi (1988). The $N$-demethylation of aminopyrine was determined by measuring the production of formaldehyde using the Nash reagent (Nash, 1953). Aniline hydroxylation 
Table 3. Expt 1. Influence of different types of dietary lipids $(150 \mathrm{~g} / \mathrm{kg}$ diet $)$ on food intake, body-weight gain, liver weight and liver microsomal cytochrome P-450 content in rats

(Mean values and pooled standard deviations)

\begin{tabular}{|c|c|c|c|c|c|c|}
\hline \multirow[b]{2}{*}{ Dietary group } & \multirow[b]{2}{*}{$n$} & \multirow{2}{*}{$\begin{array}{l}\text { Food intake } \\
(\mathrm{g} / 21 \mathrm{~d})\end{array}$} & \multirow{2}{*}{$\begin{array}{l}\text { Body-wt gain } \\
\quad(\mathrm{g} / 21 \mathrm{~d})\end{array}$} & \multicolumn{2}{|r|}{ Liver-wt } & \multirow{2}{*}{$\begin{array}{l}\text { Cytochrome P-450 } \\
\text { (nmol/mg protein) }\end{array}$} \\
\hline & & & & (g) & (g/kg body-wt) & \\
\hline Olive oil & 5 & $348 \cdot 5$ & $124 \cdot 0$ & $10 \cdot 1$ & $40 \cdot 9$ & $0 \cdot 64$ \\
\hline Lard & 5 & $349 \cdot 9$ & $130 \cdot 6$ & $10 \cdot 1$ & $40 \cdot 1$ & 0.73 \\
\hline Soya-bean oil & 6 & $342-!$ & $129 \cdot 3$ & $9 \cdot 6$ & $39 \cdot 1$ & $0.89^{* \dagger}$ \\
\hline Pooled SD $\ddagger$ & 13 & $50 \cdot 3$ & 16.0 & 1.0 & 2.9 & $0 \cdot 10$ \\
\hline
\end{tabular}

* Significantly different from the olive oil group $(P<0 \cdot 01)$.

$\dagger$ Significantly different from the lard group $(P<0.05)$.

$\ddagger$ Standard errors of differences between means are given by SD $\times(1 / n+1 / m)^{1 / 2}$ where $n$ and $m$ are the numbers of rats in the two groups being compared.

was determined by measuring the formation of $p$-aminophenol as described by Imai et al. (1966). Liver microsomal protein was measured by the method of Lowry et al. (1951).

\section{Statistical analysis}

Statistical significance of differences between mean values was assessed by analysis of variance (ANOVA) and Duncan's multiple-range test (Duncan, 1957).

\section{RESULTS}

\section{Expt 1}

Effects of dietary olive oil, lard or soya-bean oil on food intake, body-weight gain, liver weight and liver microsomal cytochrome P-450 content were examined in Expt 1 and the results are presented in Table 3 . There were no significant differences in the food intake, body-weight gain and liver weight among the three dietary groups. The liver microsomal cytochrome P-450 content of the soya-bean oil group was significantly higher than those of the olive oil and lard groups, where the cytochrome P-450 contents corresponded to the $18: 2 n-6$ and $18: 3 n-3$ contents of dietary lipids.

\section{Expt 2}

In Expt 2, lard, soya-bean oil, sardine oil and an equal mixture of each oil were examined. Food intake, body-weight gain and liver weight are shown in Table 4. No significant differences in food intake, body-weight gain and total liver weight among the four dietary groups were recognized but there were significant differences in the liver weight per $\mathrm{kg}$ body-weight between the lard and soya-bean oil groups, and between the sardine-oil group and both the soya-bean oil and oil-mixture groups. Changes in the mixed function oxidases and pentobarbital-induced sleeping time are shown in Table 5. It was noticed that the cytochrome P-450 content and the aminopyrine $N$-demethylase activity varied in a similar manner. The aminopyrine $N$-demethylase activity of the soya-bean oil group was significantly higher than that of the lard group and the cytochrome P-450 content of the soya-bean oil group also tended to be higher than that of the lard group but the differences were not significant.

While there were no significant differences in the cytochrome P-450 content and aminopyrine $N$-demethylase activity among the soya-bean oil, sardine oil and oil-mixture 
Table 4. Expt 2. Influence of different types of dietary lipids $(150 \mathrm{~g} / \mathrm{kg}$ diet $)$ on food intake, body-weight gain and liver weight in rats

(Mean values and pooled standard deviations)

\begin{tabular}{|c|c|c|c|c|c|}
\hline \multirow[b]{2}{*}{ Dietary group } & \multirow[b]{2}{*}{$n$} & \multirow[b]{2}{*}{$\begin{array}{l}\text { Food intake } \\
(\mathrm{g} / 15 \mathrm{~d})\end{array}$} & \multirow[b]{2}{*}{$\begin{array}{l}\text { Body-wt gain } \\
\text { (g/15 d) }\end{array}$} & \multicolumn{2}{|c|}{ Liver-wt } \\
\hline & & & & (g) & $\begin{array}{l}\text { (g/kg body- } \\
\text { wt) }\end{array}$ \\
\hline Lard & 9 & $242 \cdot 4$ & $118 \cdot 4$ & $11 \cdot 1$ & $50 \cdot 5$ \\
\hline Soya-bean oil & 9 & $235 \cdot 7$ & $123 \cdot 4$ & 10.5 & $46 \cdot 8^{*}$ \\
\hline Sardine oil & 9 & $219 \cdot 2$ & 117.0 & $11 \cdot 4$ & $52 \cdot 7 \dagger+$ \\
\hline Oil mixture§ & 9 & $224 \cdot 1$ & 116.9 & $10 \cdot 5$ & $48 \cdot 1$ \\
\hline Pooled SD \| & 32 & $26 \cdot 1$ & $14 \cdot 4$ & 1.4 & $3 \cdot 7$ \\
\hline
\end{tabular}

* Significantly different from the lard group $(P<0.05)$.

$\dagger$ Significantly different from the soya-bean oil group $(P<0.01)$.

\$ Significantly different from the oil-mixture group $(P<0.05)$.

$\S$ An equal mixture of lard, soya-bean oil and sardine oil.

If Standard errors of differences between means are given by SD $\times(1 / n+1 / m)^{1 / 2}$ where $n$ and $m$ are the numbers of rats in the two groups being compared.

groups, the contents and the activities were significantly higher for both the sardine-oil and oil-mixture groups than those of the lard group. Cytochrome $b_{5}$ content and aniline hydroxylase activity did not change significantly in the four dietary groups. NADPHcytochrome $c$ reductase activity in the sardine-oil group was significantly higher than those of the other three groups. Pentobarbital-induced sleeping time varied inversely with the changes in cytochrome P-450 content and aminopyrine $N$-demethylase activity in the three single dietary lipid groups but not in the oil-mixture group and the sleeping time was shortest in the sardine-oil group.

\section{DISCUSSION}

The present experiments were conducted to extend and confirm the findings of Hammer $\&$ Wills (1979) on the influence of dietary $18: 2 n-6,20: 5 n-3$ and $22: 6 n-3$ on the activity of the liver microsomal mixed function oxidase system.

In Expt 1 the effect of olive oil, lard or soya-bean oil $(150 \mathrm{~g} / \mathrm{kg}$ diet $)$ on the liver microsomal cytochrome P-450 content was investigated. The result suggested that cytochrome P-450 content increased as the 18:2n-6 content of dietary lipids increased. The cytochrome P-450 content also paralleled the $18: 3 n-3$ content of dietary lipids and this might imply that $18: 3 n-3$ also influences the activity of the liver microsomal mixed function oxidase system. This conclusion is supported by the observation that the activities of liver microsomal aminopyrine $N$-demethylase and hexobarbital oxidase are similar in rats fed on dietary maize oil rich in 18:2n-6 and linseed oil rich in 18:3n-3 (Century, 1973).

However, edible oils also contain other material such as non-saponifiable compounds, including tocopherols (vitamin E) and sterols. These substances can influence the activity of the liver microsomal mixed function oxidase system. Vitamin E deficiency is generally associated with a decrease in the activity of the mixed function oxidase system (Rowe $\&$ Wills, 1976; Zannoni \& Sato, 1976). The vitamin E levels of the four diets with different test lipids were within the normal range of dietary vitamin $E$. We have observed that a normal range of vitamin $\mathrm{E}$ ingestion has no effect on the liver microsomal mixed function oxidase system, although higher levels of the vitamin, over $335 \mathrm{mg} / \mathrm{kg}$ diet, enhance the aminopyrine $N$-demethylase activity and cytochrome P-450 content (M. Saito and M. 


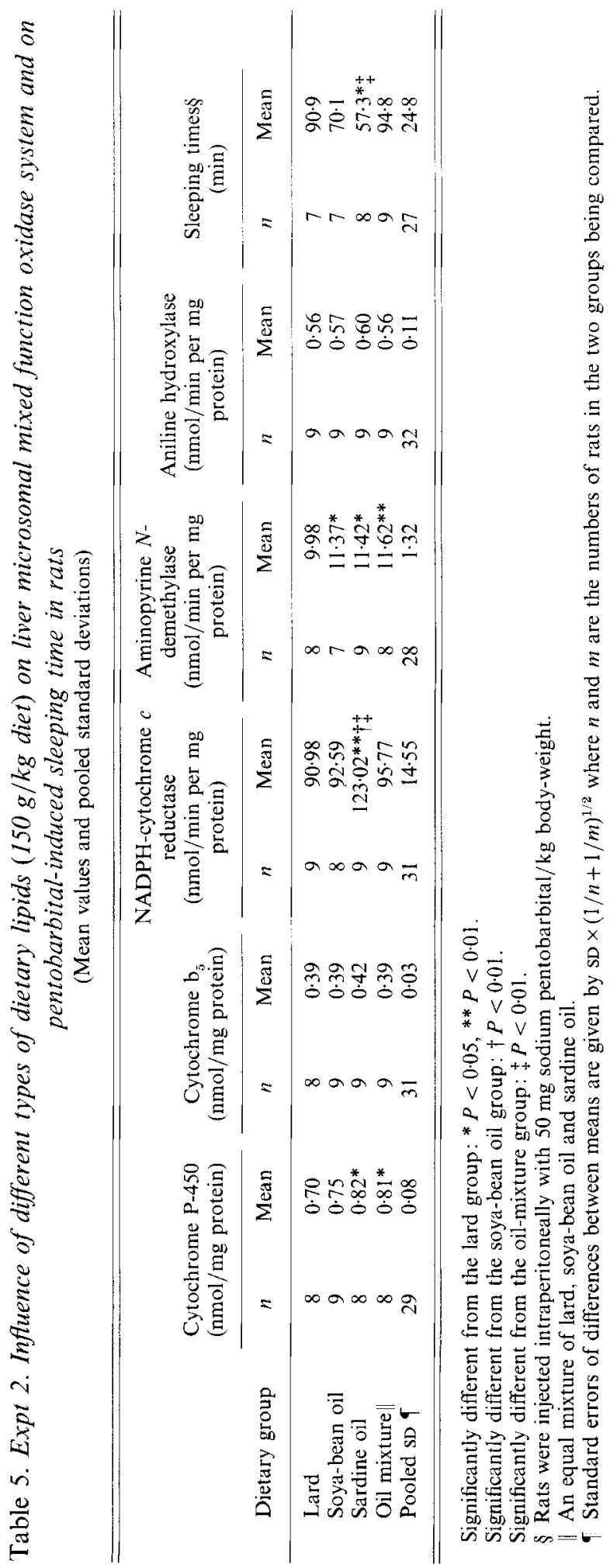


Yamaguchi, unpublished results). Sitosterol and cholesterol have no effect on the change in liver microsomal cytochrome P-450 content induced by phenobarbitone (Marshall \& McLean, $1971 b$ ). However, the non-saponifiable compounds in herring oil, which include cholesterol and squalene, increase the activity of aminopyrine $N$-demethylase and the content of cytochrome P-450 (Lambert \& Wills, 1977). Therefore, further studies will be necessary to determine the effects of non-triacylglycerol components in oils on the liver microsomal mixed function oxidase system.

In Expt 2 the effects on the liver microsomal mixed function oxidase system of sardine oil (rich in 20:5n-3 and 22:6n-3) were compared with the effects of lard and soya-bean oil. Aniline hydroxylase activity and cytochrome $b_{5}$ content remained unchanged in the four dietary groups. However, liver microsomal aniline hydroxylase activity and cytochrome $\mathbf{b}_{5}$ content decrease in rats given a fat-free diet (Norred \& Wade, 1972; Wade \& Norred, 1976). NADPH-cytochrome $c$ reductase activity was significantly higher in the sardine-oil group than in the other three dietary lipid groups. Since no significant difference was recognized in NADPH-cytochrome $c$ reductase activity among lard, soya-bean oil and the oil-mixture groups, the amounts of highly unsaturated fatty acids such as $20: 5 n-3$ and $22: 6 n-3$ derived from the oil-mixture diet ( $50 \mathrm{~g}$ sardine oil $/ \mathrm{kg}$ diet) were not enough to enhance the activity to the same level as that in the sardine-oil group. In addition, no significant change has been reported in liver microsomal NADPH-cytochrome $c$ reductase activity in rats fed on a fatfree diet (Wade et al. 1972; Wade \& Norred, 1976), suggesting that NADPH-cytochrome $c$ reductase is not influenced by dietary $18: 2 n-6$ and $18: 3 n-3$. This might explain why there was no significant difference in NADPH-cytochrome $c$ reductase activity among lard, soyabean oil and oil-mixture groups.

The aminopyrine $N$-demethylase activities and cytochrome P-450 contents of the soyabean oil, sardine-oil and oil-mixture groups were similar, but they were higher than those of the lard group. The low levels of aminopyrine $N$-demethylase and cytochrome P-450 in the lard group appeared to suggest that the rather high amounts of $18: 2 n-6$ and $18: 3 n-3$ derived from soya-bean oil ( $150 \mathrm{~g}$ soya-bean oil $/ \mathrm{kg}$ diet) stimulated the activity of these enzymes. Alternatively, the higher intake of saturated fatty acids from lard may have increased the proportion of saturated fatty acids in microsomal membrane phospholipids and, thus, altered the membrane conformation and fluidity leading to a low activity of the mixed function oxidases. The latter possibility would imply that an appropriate proportion of $18: 2 n-6$ and $18: 3 n-3$ relative to saturated fatty acids is required to activate the liver microsomal mixed function oxidase system. However, the intake of $18: 2 n-6$ from the lard diet was considerably greater than the amounts required to prevent essential fatty acid deficiency. Dietary $20: 5 n-3$ and $22: 6 n-3$ in sardine oil as well as $18: 2 n-6$ and $18: 3 n-3$ also seem to stimulate the mixed function oxidase system. Hammer \& Wills (1979) used herring oil, rich in eicosenoic $(20: 1 n-11)$ and docosenoic $(22: 1 n-11)$ acids as well as $20: 5 n-3$ and $22: 6 n-3$, whereas we used sardine oil, low in these monoenes. In both these studies a similar increase in aminopyrine $N$-demethylase activity was observed, which would suggest that 20:5n-3 and 22:6n-3 might be responsible for the increased activity.

Pentobarbital-induced sleeping time reflects the activity of the mixed function oxidase system in vivo. It altered inversely with changes in liver microsomal cytochrome P-450 content and aminopyrine $N$-demethylase activity in the three single dietary lipid groups but not in the oil-mixture group, assuming that liver microsomal metabolic activity with pentobarbital in vivo showed changes similar to those of cytochrome P-450 content and aminopyrine $N$-demethylase activity in vitro in liver microsomes. Since the sleeping time of the oil-mixture group was significantly longer than that of the sardine-oil group, the metabolic activity with pentobarbital in vivo in the oil-mixture group was thought to be low compared with that in the sardine-oil group. Thus, the amounts of highly unsaturated 
fatty acids such as $20: 5 n-3$ and $22: 6 n-3$ derived from the oil-mixture diet (50 g sardine oil $/ \mathrm{kg}$ diet) would be insufficient to keep the metabolic activity with pentobarbital in vivo to the same level as that in the sardine-oil group, although the precise reason for this is unclear. In this respect the sleeping time showed similar changes to those of NADPHcytochrome $c$ reductase activity.

The results obtained here further support the findings reported by Hammer \& Wills (1979) for cytochrome P-450 and cytochrome $b_{5}$ contents, aniline hydroxylase activity and in vivo pentobarbital-induced sleeping time as well as aminopyrine $N$-demethylase activity. Therefore, dietary 18:2n-6 and 18:3n-3 stimulate the liver microsomal mixed function oxidase system, and highly unsaturated fatty acids such as $20: 5 n-3$ and $22: 6 n-3$ in fish oil also seemed to function in a manner similar to $18: 2 n-6$ and $18: 3 n-3$.

Future studies will be necessary to substantiate the respective functions by using pure fatty acids such as $18: 2 n-6,18: 3 n-3,20: 5 n-3$ or $22: 6 n-3$. The present study did not examine the influence of dietary lipids on the induction of the mixed function oxidase system stimulated by drugs such as phenobarbital and 3-methylcholanthrene. However, it has been reported that increasing the proportion of dietary unsaturated fatty acids enhances the induction of the liver microsomal mixed function oxidase system by phenobarbital (Marshall \& McLean, $1971 a, b$; Century, 1973). It would be predicted from our results that the enhancement of the induction of the mixed function oxidase system would decrease in the order: sardine oil $>$ soya-bean oil $>$ lard $>$ olive oil.

The authors thank Ajinomoto Co. Inc. and Taiyo Fishery Co. Ltd for the generous gifts of soya-bean oil and sardine oil respectively.

\section{REFERENCES}

Anderson, K. E., Conney, A. H. \& Kappas, A. (1982). Nutritional influences on chemical biotransformations in humans. Nutrition Reviews 40, 161-171.

Bieri, J. G., Stoewsand, G. S., Briggs, G. M., Phillips, R. W., Woodard, J. C. \& Knapka, J. J. (1977). Report of the American Institute of Nutrition Ad Hoc Committee on standards for nutritional studies. Journal of Nutrition 107, 1340-1348.

Century, B. (1973). A role of the dietary lipid in the ability of phenobarbital to stimulate drug detoxification. Journal of Pharmacology and Experimental Therapeutics 185, 185-194.

Clinton, S. K., Mulloy, A. L. \& Visek, W. J. (1984). Effects of dietary lipid saturation on prolactin secretion, carcinogen metabolism and mammary carcinogenesis in rats. Journal of Nutrition 114, 1630-1639.

Duncan, D. B. (1957). Multiple range tests for correlated and heteroscedastic means. Biometrics 13, $164-176$.

Hammer, C. T. \& Wills, E. D. (1979). The effect of dietary fats on the composition of the liver endoplasmic reticulum and oxidative drug metabolism. British Journal of Nutrition 41, 465 475.

Hopkins, G. J. \& West, C. E. (1976). Effect of dietary fats on pentobarbitone-induced sleeping times and hepatic microsomal cytochrome P-450 in rats. Lipids 11, 736-740.

Imai, Y., Ito, A. \& Sato, R. (1966). Evidence for biochemically different types of vesicles in the hepatic microsomal fraction. Journal of Biochemistry, Tokyo 60, 417-428.

Kaschnitz, R. (1970). Aryl 4-hydroxylase, cytochrome P-450 and microsomal lipids in essential fatty acid deficiency. Hoppe-Seyler's Zeitschrift für Physiologische Chemie 351, 771-774.

Laitinen, M., Hietanen, E., Vainio, H. \& Hanninen, O. (1975). Dietary fats and properties of endoplasmic reticulum. I. Dietary lipid induced changes in composition of microsomal membranes in liver and gastroduodenal mucosa of rat. Lipids 10, 461-466.

Lambert, L. \& Wills, E. D. (1977). The effect of dietary lipid peroxides, sterols and oxidised sterols on cytochrome P450 and oxidative demethylation in the endoplasmic reticulum. Biochemical Pharmacology 26, 1417-1421.

Lowry, O. H., Rosebrough, N. J., Farr, A. L. \& Randall, R. J. (1951). Protein measurement with the Folin phenol reagent. Journal of Biological Chemistry 193, 265-275.

Lu, A. Y. H. (1976). Liver microsomal drug-metabolizing enzyme system: functional components and their properties. Federation Proceedings 35, $2460-2463$.

Marshall, W. J. \& McLean, A. E. M. (1971 a). Dietary lipid requirements for hepatic microsomal enzyme induction in the rat. Proceedings of the Nutrition Society 30, 66A-67A

Marshall, W. J. \& McLean, A. E. M. $(1971 b)$. A requirement for dietary lipids for induction of cytochrome P-450 by phenobarbitone in rat liver microsomal fraction. Biochemical Journal 122, 569-573. 
Meydani, M., Blumberg, J. B. \& Hayes, K. C. (1985). Dietary fat unsaturation enhances drug metabolism in Cebus but not in Squirrel monkeys. Journal of Nutrition 115, 573-578.

Miller, O. N. (1976). Nutrition and drug metabolism. Introduction. Federation Proceedings 35, 2459.

Mino, M., Tamai, H., Yasuda, K., Yamada, C., Igarashi, O., Hayashi, M., Hirahara, F., Katsui, G. \& Kijima, S. (1988). Biopotencies of tocopherol analogues as determined by diarulic acid induced hemolysis in rats. Vitamins (Japan) 62, 241-246.

Nash, T. (1953). The colorimetric estimation of formaldehyde by means of the Hantzsch reaction. Biochemical Journal 55, 416-421.

Norred, W. P. \& Wade, A. E. (1972). Dietary fatty acid-induced alterations of hepatic microsomal drug metabolism. Biochemical Pharmacology 21, 2887-2897.

Omura, T. \& Sato, R. (1964). The carbon monoxide-binding pigment of liver microsomes. I. Evidence for its hemoprotein nature. Journal of Biological Chemistry 239, 2370-2378.

Omura, T. \& Takesue, S. (1970). A new method for simultaneous purification of cytochrome $b_{5}$ and NADPHcytochrome c reductase from rat liver microsomes. Journal of Biochemistry 67, 249-258.

Rowe, L. \& Wills, E. D. (1976). The effect of dietary lipids and vitamin E on lipid peroxide formation, cytochrome P-450 and oxidative demethylation in the endoplasmic reticulum. Biochemical Pharmacology 25, 175-179.

Saito, M. \& Yamaguchi, M. (1988). Influence of excessive ascorbic acid dose on liver microsomal mixed function oxidase system in guinea pigs. Journal of Clinical Biochemistry and Nutrition 4, 123-137.

Wade, A. E. \& Norred, W. P. (1976). Effect of dietary lipid on drug-metabolizing enzymes. Federation Proceedings 35, 2475-2479.

Wade, A. E., Wu, B. \& Caster, W. O. (1972). Relationship of dietary essential fatty acid consumption to hepatic drug hydroxylation. Pharmacology 7, 305-314.

Zannoni, V. G. \& Sato, P. H. (1976). The effect of certain vitamin deficiencies on hepatic drug metabolism. Federation Proceedings 35, 24642469. 